\title{
Sujeito e discurso da racionalidade técnica na sociedade mediática
}

\author{
Angela Pintor dos Reis
}

\section{Resumo}

Este ensaio discute em que condições a

racionalidade técnica constitui um composto com

a sociedade mediática para a constituição de um

sujeito normalizado. Como suporte à discussão

são desenvolvidas relações entre dispositivos de

construção do sujeito e dispositivos de três tipos

de discurso, a saber: 0 do mestre moderno, 0

universitário e o competente. Sujeito e discurso

são conceitualmente considerados no contexto da

teoria lacaniana, sendo o discurso compreendido

como o liame social a partir do qual o sujeito se

constrói e sobre o qual se projeta. A racionalidade

técnica é considerada como ideologia de dominação,

nos termos desenvolvidos por Marcuse, Habermas,

Weber e Heidegger.

\section{Palavras-Chave}

Racionalidade técnica. Sociedade mediática. Sujeito. Discurso. Dominação.

Angela Pintor dos Reis I angelapintor@terra.com.br Doutoranda pelo Programa de Pós-Graduação em Comunicação e Semiótica da Pontifícia Universidade Católica de São Paulo (PUC-SP). Membro do Centro de Pesquisas em Comunicação e Cibercultura (CENCIB).

\section{$1 \mathrm{~A}$ racionalidade técnica como refúgio}

No contexto deste ensaio a técnica é considerada como o projeto social-histórico de uma sociedade que construiu para si um modelo de racionalidade que lhe assegurasse um modo específico de dominação sobre 0 ente humano e as coisas (MARCUSE, 1998, p. 132). Embora esse modelo de racionalidade tenha se desenvolvido mais robustamente na história do modo de produção capitalista, sendo mais visível hoje na dimensão econômica e administrativa da cultura, pode-se considerar que ele lhe antecede na medida em que se assenta sobre o princípio da dominação, estando este amparado tanto pela história psíquica do sujeito quanto pela dinâmica evolutiva dos modos de produção econômica. Como observa Weber (2004, p. 50), a ganância - no sentido da vontade e da ação desenfreada e sem limites em direção à obtenção de uma vantagem contra alguém - "é tão velha quanto a história da humanidade que conhecemos", estando calcada na "luta entre os homens" (WEBER, 1999, p. 57) para a satisfação de necessidades, satisfação esta que pode se 
realizar como um modo de "desencobrimento" (HEIDEGGER, 2008, p. 18-19) imposto pelo sujeito à natureza e ao próprio ente humano.

Racionalidade e dominação compuseram as forças de desenvolvimento do capitalismo até seu modo contemporâneo, instituindo um modelo mental instrumental e orientado a fins. Em sua história, a atividade econômica capitalista se vale do referido modelo para se afirmar politicamente como "tráfego social regido pelo direito privado burguês e [pela] dominação burocrática", que dependem, para seu pleno desenvolvimento, de um sistema de pensamento tecnocrático (HABERMAS, 2006, p.

45). Nessas condições,

Racionalização significa, em primeiro lugar, a ampliação das esferas sociais, que ficam submetidas aos critérios da decisão racional. $A$ isso corresponde a industrialização do trabalho social com a consequência de que os critérios da acção instrumental penetram também noutros âmbitos da vida (urbanização das formas de existência, tecnificação do tráfego e da comunicação). Em ambos os casos, trata-se da implantação do tipo de acção social relativamente a fins (HABERMAS, 2006, p. 45).

\section{A racionalização, como aponta Habermas}

(2006) no contexto da análise crítica da obra de Marcuse - no que esta diz respeito à discussão da racionalidade técnica em Weber -, mantém relações de dependência com a ideia de progresso científico e técnico, em bloco, apresentando-se como um sistema simbólico destinado a atender necessidades de relacionamento do ente humano com a natureza, com 0 ambiente, com o mundo; necessidades estas que podem ser consideradas, em última instância, como equivalentes a necessidades de dominação, pois destas viriam as condições para a sobrevivência (material e simbólica) ou a continuação da existência do sujeito em um determinado ambiente.

0 conhecimento tecnocientífico, assim, forneceu meios para a almejada satisfação de necessidades de relacionamento do ente humano com a natureza, 0 ambiente, 0 mundo, e nessa esteira criou uma estrutura de justificação para os processos de dominação. Nesse raciocínio, se natureza, ambiente e mundo forem entendidos na qualidade de categorias representativas do outro para o sujeito - como quem (ou o que) ocupa um lugar simbólico para ele (ROUDINESC0; PLON, 1998, p. 558-560) -, temse a racionalidade técnica como um repertório de mediação entre sujeito-natureza, sujeito-mundo, sujeito-ambiente, sujeito-outro, que se destina a viabilizar um projeto existencial por meio da metabolização de forças dialeticamente ligadas a incerteza e a dominação.

Cultivada nas engrenagens do conhecimento científico, a racionalidade técnica é institucionalizada pelo sujeito como conjunção entre meios de produção e esquema de construção de sentido, que fornece elementos para a significação das ações dos indivíduos em uma determinada sociedade. A técnica ganha condições máximas de racionalidade apoiando-se no conhecimento científico, quando este instrumenta 
o sujeito para que lhe seja possível empregar recursos, consciente e planejadamente, para a obtenção do melhor resultado em comparação com outros resultados possíveis para a mesma ação (WEBER, 1999, p. 38).

Nessa maneira de entender a técnica, o critério da racionalidade está impresso no que Weber (1999, p. 38, grifo do autor) denomina "princípio do esforço mínimo", que "corresponde ao resultado ótimo em comparação com os meios a serem aplicados (não 'com os meios absolutamente - mínimos')".

Em que pese 0 fato de 0 princípio do esforço mínimo ter sido conceituado no contexto da economia da sociedade, é tentador 0 exercício de relacioná-lo com o binômio princípio do prazer/princípio de realidade advindo da psicanálise. Por princípio do prazer considerase aqui, com base em Lacan (1992, p. 47), "0 princípio da menor tensão, da tensão mínima a manter para que subsista a vida". 0 princípio de realidade, ao contrário, representa, grosso modo, as restrições e os constrangimentos assumidos pelo sujeito como necessários para sua adaptação ao ambiente (ROUDINESC0; PLON, 1998, p. 603). Complementarmente, em Freud (2010, p. 162) encontra-se que 0 princípio do prazer é visto como "sempre incitado por uma tensão desprazerosa e [que] toma uma direção tal que 0 seu resultado final coincide com um rebaixamento dessa tensão, ou seja, com uma evitação do desprazer ou a geração do prazer".
À primeira vista, princípio do esforço mínimo e princípio do prazer/princípio de realidade podem ser vistos como associados quando se considera que a racionalidade técnica enuncia, na qualidade de sistema ideológico, um modo de existência que representa um estado ideal de conexão, de associação - ou de comunicação - entre sujeito e outro, sujeito e mundo. Essa cena ideal de compartilhamento e de entendimento - entre sujeito e outro, sujeito e mundo - traduz-se como experiência em que a diferença, a falibilidade, 0 indeterminado, a incerteza estão ausentes, isto é, trata-se de uma experiência tipicamente idealizada no campo do princípio do prazer. É como se a racionalidade técnica, por meio de seu sistema simbólico, acenasse para 0 sujeito com um modo determinista de pensamento, por meio do qual e em nome do qual se buscará, diuturnamente, 0 ocultamento, 0 esquecimento, 0 apagamento das vicissitudes do outro por estas estarem simbolicamente situadas no campo do princípio de realidade, por exigirem do indivíduo um esforço de adaptação ou um enfrentamento com a diferença.

Em outras palavras, ao funcionar como um sistema simbólico que (1) representa a cultura dominante em relação a qual o sujeito tende a desenvolver uma dialogia para se sentir aceito, reconhecido e pertinente a um determinado ambiente sociocultural; (2) institui modelos de pensamento e de conduta que conclamam, subliminarmente, a esterilização da subjetividade 
para que esta não coloque obstáculos para a consecução dos objetivos econômicos da sociedade; e (3) torna tácita a dominação entre sujeitos, experimentada como modo de prazer pela predação do outro e do ambiente, a ideologia da racionalidade técnica enuncia possibilidades de o sujeito experimentar um estado comunicativo com o outro, simbolicamente equivalente ao prazer vivenciado no circuito fechado e imperturbável entre lactente e seio materno (ROUDINESCO; PLON, 1998, p. 603).

Quando Freud (2010, p. 162) desenvolve seu entendimento do princípio do prazer, como antes visto, está apontando, explicitamente, para a existência de uma "economia" dos processos psíquicos; Weber, de seu lado, ao analisar a racionalidade técnica circunscrita ao princípio do esforço mínimo, não encaminha, expressamente, a discussão para o campo psicossocial ou sociopsicanalítico, mas abre espaço para que seja considerada a existência de um subterrâneo no referido modelo ideológico, no qual subjaz o sujeito abandonado à própria sorte, em total cumplicidade com as forças psíquicas que o regem e por meio das quais ele se constrói.

Por essa perspectiva é possível reler o que foi desenvolvido por Weber (1999, p. 187-580) a respeito de uma sociologia da dominação, considerando que esse conjunto teórico remete à existência do que poderia ser chamado de "economia do sujeito", na medida em que por sujeito pode se entender o indivíduo regido pela dinâmica do binômio princípio do prazer/ princípio de realidade, que somente faz sentido na circunstância da alteridade. 0 outro, nesse caso particular, pode ser visto também em sua natureza econômica, estando difusamente representado pelas instituições sociais economicamente orientadas, entre as quais está o empreendimento capitalista lato sensu e os media como produtores e articuladores de sentido na sociedade. Desse modo, o que pode ser chamado de "economia do sujeito" diz respeito ao modo como o indivíduo se constrói a partir das relações de dominação, que embora sejam economicamente orientadas na situação em análise, não são exclusivamente vinculadas ou dependentes das necessidades econômicas, como adverte o próprio Weber (1999).

\section{A lógica da dominação}

0 que importa considerar na análise da dominação, segundo Weber (1999, p. 192, grifos do autor), é sua "existência efetiva", concretizada no fato de "uma autoridade que pretende para si o direito de emitir determinados mandados encontrar, num grau socialmente relevante, efetivamente a obediência”. A partir desse firmamento conceitual, Weber desenvolve sua sociologia categorizando modos de manifestação da dominação no contexto da administração porque, segundo ele, "toda dominação manifesta-se e funciona como administração" e "toda administração precisa, de alguma forma, da dominação, pois, para dirigi-la, é mister que certos poderes de mando se encontrem nas mãos de alguém" (WEBER, 1999, p. 193). 
0 esquema da dominação no contexto da administração acomoda, por necessidade de perpetuação do próprio esquema, a racionalidade técnica com tripla função: (1) a de modelo mental orientado a fins; (2) a de especialização técnica que representa 0 domínio de conhecimento formal apto a produzir 0 resultado ótimo em comparação com os meios a serem aplicados (princípio do esforço mínimo, como já visto) e, por último, condensando as duas funções anteriores; (3) a de ideologia de dominação pelo fato de aparelhar técnica e simbolicamente 0 sujeito para 0 exercício do poder (administrativo) sobre o outro. A dominação exercida por uma minoria detentora do conhecimento tecnocientífico sobre uma maioria se processa eficazmente, nessas condições, quando

os dominadores guardam segredo de suas intenções, das decisões e do conhecimento, atitude que se torna mais difícil e improvável com cada acréscimo. Todo aumento do dever de guardar o "segredo oficial" é um sintoma da intenção dos dominadores de intensificar o poder por eles exercido ou da convicção de este estar exposto a uma ameaça crescente. Toda dominação que pretenda continuidade é, em algum ponto decisivo, dominação secreta (WEBER, 1999, p. 196, grifos do autor).

A engrenagem da dominação, portanto, pressupõe um sujeito barrado pelo discurso do outro, isto é, resultante do discurso do mestre - este posto como um significante simbolicamente projetado (como será visto adiante) - e representado por um saber menos (LACAN, 1992); sustenta-se, assim, sobre uma relação associativa [...], no fato de que determinado círculo de pessoas, habituadas a obedecer às ordens de líderes e interessadas pessoalmente na conservação da dominação, por participarem desta e de suas vantagens, se mantêm plenamente disponíveis e repartem internamente aqueles poderes de mando e de coação que servem para conservar a dominação ("organização"). Àquele líder ou àqueles líderes cujo poder de mando pretendido e de fato exercido não lhes foi delegado por outros líderes denominaremos "senhores", e às pessoas que na forma mencionada se põem a sua disposição especial, de seu "aparato" (WEBER, 1999, p. 196-197, grifos do autor).

As categorias "mestre" e "discurso", associadas aqui à sociologia da dominação de Weber, são consideradas, na teoria lacaniana, articuladoras do sujeito. 0 "discurso" corresponde a uma estrutura social com a qual o sujeito está enredado e que lhe confere construção lógica sobre si próprio, sobre a alteridade e o mundo (GONÇALVES, 2000, p. 25); nas tramas do discurso como um laço social que o enreda, o sujeito significa a si próprio em relação a significantes, e ao proceder assim, significa os significantes que estruturam e organizam 0 discurso (GONÇALVES, 2000, p. 27). Nesse sistema de representações encontra-se a figura do mestre em relação à qual o sujeito se significará, de modo que o sujeito pode ser entendido como "efeito do funcionamento do significante [mestre]" (GONÇALVES, 2000, p. 28). A condição de mestre é ocupada, nessa circunstância, por quem ou por aquele "tomado como único e uno em sua sabedoria, situação em que 0 argumento de autoridade alcança a máxima 
eficácia" (GONÇALVES, 2000, p. 19). Isso leva ao entendimento de que 0 sujeito representa-se para si próprio como subtraído de um saber que atribui ao mestre, como um algo a mais de que este é dotado, colocando-se o sujeito, assim, na posição de quem se encontra extraído ou diminuído de algo - por este mecanismo, o sujeito coloca-se na posição de dominado.

Essa leitura convergente da dinâmica da dominação e do discurso do mestre faz lembrar o que Heidegger (2008, p. 18-19) discute sobre a essência da técnica moderna, quando a esta associa 0 ato de desencobrimento do outro, no sentido da exploração que o sujeito impõe sobre algo (a natureza) ou alguém (o ente humano) com a pretensão de obter energia capaz de ser beneficiada e armazenada. A técnica moderna comparece no processo social-histórico como 0 empreendimento capitalista cuja mentalidade busca "o máximo rendimento possível com 0 mínimo de gasto" (HEIDEGGER, 2008, p. 19), ${ }^{1}$ na medida em que

\footnotetext{
0 desencobrimento que domina a técnica moderna, possui, como característica, o pôr, no sentido de explorar. Esta exploração se dá e acontece num múltiplo movimento: a energia escondida na natureza é extraída, 0 extraído vê-se transformado, o transformado, estocado, 0 estocado, distribuído, o distribuído, reprocessado. Extrair, transformar, estocar, distribuir, reprocessar são todos modos de desencobrimento. Todavia, este desencobrimento não se dá simplesmente.
}

\begin{abstract}
Tampouco, perde-se no indeterminado. Pelo controle, o desencobrimento abre para si mesmo suas próprias pistas, entrelaçadas numa trança múltipla e diversa. Por toda parte, assegura-se 0 controle. Pois controle e segurança constituem até as marcas fundamentais do desencobrimento explorador (HEIDEGGER, 2008, p. 20).
\end{abstract}

Controle e segurança podem, nessas condições, ser entendidos como dispositivos constituintes de um modo de dominação típico do posicionamento do sujeito em relação à natureza, ao ambiente, ao mundo, ao outro; posicionamento este operado pela disposição de forças no sentido da transformação do outro em "mera provisão" (HEIDEGGER, 2008, p. 20). Mas essa disposição de forças não reduz a técnica moderna "a um fazer do homem" (HEIDEGGER, 2008, p. 22); isto é, quando a força de disposição transforma algo ou alguém em provisão não está aí posto apenas 0 aspecto instrumental ou operacional da coisa. Isso porque, em sua essência, a técnica moderna corresponde a uma "com-posição" (HEIDEGGER, 2008, p. 23-28) como um sistema que estrutura, reúne e organiza 0 ente humano, as forças de disposição e a natureza. 0 sujeito, portanto, no contexto da essência da técnica moderna, desempenha papel duplo, a saber, de quem se força sobre o outro (ou a natureza) e de quem absorve a força do outro, estando, dessa maneira, na condição de sujeitado a forças das quais compartilha, reproduzindo-se a partir delas, e que 
lhe excedem. Em outras palavras, o sujeito alterna posições, desempenhando o papel de mestre ou de sujeito barrado pelo discurso do mestre.

Pode-se depreender a partir do entendimento de Heidegger que a "com-posição" à qual corresponde a essência da técnica moderna equivale à armação ou amarração, como uma trama, entre: (1) sujeito entendido como construção psíquica e social resultante do discurso do outro (LACAN, 1992, p. 11) e; (2) discurso assumido aqui como um liame social estruturado em linguagem verbal e não verbal, como um "discurso sem palavras" (LACAN, 1992, p. 11), simbolicamente um "conjunto de vozes" que emite enunciados definindo "a realidade do mundo, a razão de ser do grupo [social], a origem de seus modelos" (CASTORIADIS-AULAGNIER, 2010, p. 161, tradução nossa).

Por "conjunto de vozes" pode-se tomar a própria sociedade mediática, na medida em que esta representa a tessitura social a partir da qual 0 indivíduo se representa para si próprio e para 0 outro (SOUSA, 2000, p. 78). Ou seja, a sociedade mediática está para além dos meios e da tecnologia de comunicação quando qualifica o tecido social (SOUSA, 2000, p. 78), compondo uma tela mental para 0 exercício da alteridade ao enunciar o próprio sujeito, cobrindo-o de significações a seu próprio respeito e a respeito de quem ocupa o lugar da alteridade. 0 sujeito, assim, se constrói a partir de uma teia de relações - entrecruzadas com o repertório mediático composto por modelos de sujeito ideal - e se alimenta dessa estrutura por sua necessidade de ter coordenadas existenciais, sinalizadas pela alteridade (que pode ser exercida pelos próprios media quando estes cumprem a função do outro ou do mestre). Esse modus operandi do indivíduo abriga forças de dominação, exercitadas entre sujeitos, e se alimenta de configurações econômicas e socioculturais de época, uma vez que 0 ambiente é 0 lugar em que se processa a história psíquica do sujeito.

Essa condição basilar existencial assenta-se sobre a relação dialética estabelecida entre 0 sujeito e o outro, ocupando este a função do mestre por ser identificado como o portador de um saber e de uma verdade que 0 sujeito deseja por representarem, para ele, a presença de uma falta, como enfatiza Lacan (1992,). Grosso modo, pode-se dizer que 0 sujeito fixase em uma imagem idealizada do outro como 0 detentor de algo que representa para ele uma ausência - como uma marca gravada em sua história psíquica - produzida no contexto da experiência de separação, por diferenciação, do corpo um dia percebido como uno em relação ao corpo da mãe. 0 outro, assim, é identificado como aquele que produz uma perda (LACAN, 1992, p. 97). Essa experiência instaura uma percepção de mundo como clivagem, instituindo a figura do mestre para a qual serão atribuídas significações diferenciadas, a depender da posição que o sujeito assume em relação ao referido significante e à configuração sociocultural de época, da qual a 
sociedade mediática é um vetor. Na dinâmica do sujeito, afirma Lacan, fazendo remissão à dialética do senhor e do escravo desenvolvida por Hegel (2007, p. 142-151),

a figura inaugural do mestre e senhor, encontra sua verdade no trabalho do outro por excelência, daquele que só se sabe por ter perdido esse corpo, esse mesmo corpo em que se sustenta, por ter querido preservá-lo em seu acesso ao gozo - em outros termos, o escravo (LACAN, 1992, p. 94).

\section{A sociedade mediática como lugar do discurso do mestre moderno}

No contexto contemporâneo de uma "economia do sujeito", em que o sistema econômico organiza e explica administrativamente a existência do ente humano - contando, para isso, com a infraestrutura tecnocientífica -, vige o discurso do mestre moderno, de caráter totalitário, no sentido de advogar para si um "todo-saber" (GONÇALVES, 2000, p. 54, 57). A instância do todo-saber é fundamental para 0 discurso do mestre moderno porque nela "não há lugar para o inconsciente, que diz respeito ao saber 'do tropeço' ou 'da mancada" (GONÇALVES, 2000, p. 57); ou seja, o todo-saber implica na "exclusão do sujeito na medida do desconhecimento das vicissitudes do desejo" (GONÇALVES, 2000, p. 56) que significam a incerteza e 0 indeterminado. É nesse espaço e com esses propósitos que a racionalidade técnica se desenvolve como um saber absoluto - distribuído pelos media, estes tomados como o próprio mestre moderno ao atuarem como seu interlocutor com o sujeito - que busca uma formalização tal do mundo (e do sujeito) em que tudo é transformado em números, em objetos calculáveis, em fórmulas (LACAN, 1992, p. 84); a racionalidade técnica como discurso age esquadrinhando a realidade objetal e os modos de disposição - retomando Heidegger, como visto anteriormente - das forças produtivas do sujeito para preencher de sentido cada fragmento da vida. Trata-se de um empreendimento que almeja a normalização do mundo a partir da normalização do sujeito, como recurso para 0 enfrentamento de incertezas e vicissitudes, no plano existencial imediato, e para suportar a impermanência, considerando um horizonte simbolicamente longínquo da existência.

Pode-se dizer que a racionalidade técnica como ideologia de dominação e a sociedade mediática como seu suporte compartilham do mesmo projeto de produção de um sujeito debilitado, resultante de uma violência silenciosa caracterizada pela "atrofia da experiência" subjetiva (BENJAMIN, 1936a, 1936b, apud FERRAZ, 2011, p. 160) e pelo "rebaixamento da alteridade ao estado de coisa" (BASTOS; CABRAL; REZENDE, 2010, p. 135), tornando impossível, ou pelo menos dificultosa, a singularidade do ente humano quando este é forçado a circunscrever-se em padrões em nome da previsibilidade, do controle e da eficiência econômica (BASTOS; CABRAL; REZENDE, 2010, p. 131). 
Ao produzir clichês que prescrevem quem 0 sujeito deve ser, tanto a racionalidade técnica como modelo mental capitalista quanto a sociedade mediática na sua função de suporte desincentivam a experiência do próprio sujeito com a subjetividade, criando condições ótimas para 0 desenvolvimento de sujeitos "normopatas" como aqueles "aparentemente bem adaptados e 'normais', isto é, sem conflito psíquico ruidoso" (FERRAZ, 2011, p. 26). A "normalidade" em questão, nas condições em que é definida pela psicanálise, é falsa ou aparente pelo fato de o "normopata" resultar de um processo de sobreadaptação defensiva contra um sofrimento psíquico importante (FERRAZ, 2011). Embora não seja possível atribuir à normopatia 0 título de doença própria da cultura contemporânea - por se considerar que pode haver, no ente humano, uma inclinação para a "normalidade", dependente mais do contexto de sociabilidade particular, como as relações familiares, do que do ambiente macrossocial -, "não podemos desprezar o fato de que a experiência do contato significativo com a subjetividade, como supõem tantos autores que têm se dedicado à psicopatologia atual, tem sido desencorajada, ou até mesmo obstruída, pelas imposições do modo de vida hegemônico de nosso tempo" (FERRAZ, 2011, p. 162, grifo do autor).

Há de se considerar, também, que o mundo do trabalho - campo de pleno desenvolvimento da racionalidade técnica e, portanto, da burocracia normalizante; ao mesmo tempo campo de produção do sujeito -, pode ser entendido como o lugar em que a interação social é tratada como luta contra a natureza considerada perigosa do ente humano (LORENZER, 2001, p. 125, tradução nossa), especificamente no que esta diz respeito à subjetividade e ao afeto, percebidos como fontes das vicissitudes existenciais e comportamentais. Na medida em que a práxis do indivíduo pressupõe uma relação dialética entre "natureza interior e natureza exterior" (FERRAZ, 2011, p. 119, tradução nossa), o sujeito inicia a assimilação das forças e dos códigos desse contexto macrossocial - que pode ser denominado cultura ou sociedade mediática, se se quiser considerar uma caracterização de época - já na socialização primária, ou seja, nas primeiras experiências relacionais estabelecidas no circuito mãe-filho. A função mãe, nesse entendimento, "se estrutura como parte do trabalhador genérico" e "precisamente por isso sua conduta se caracteriza pelas limitações a que está exposto o trabalhador genérico pelas relações de produção petrificadas" (LORENZER, 2001, p. 119, tradução nossa). Em outras palavras, tanto a racionalidade técnica nas dimensões de ideologia e modus operandi do mundo da produção - quanto a sociedade mediática como um coro que dita o sujeito contemporâneo, relembrando CastoriadisAulagnier, conforme visto anteriormente, demarcam as possibilidades existenciais do ente humano desde seu primeiro estágio de socialização (LORENZER, 2001, p. 120, tradução nossa). 


\section{Do discurso do mestre moderno ao discurso competente}

Pode-se considerar, portanto, que a racionalidade técnica e a sociedade mediática compõem o liame social do qual emerge o sujeito e sobre o qual ele se projeta para significar a si próprio, comparecendo nessa trama como instrumentos infraestruturais do sistema de produção capitalista em seu estágio avançado. Criam, assim, condições para a coisificação e normalização do sujeito, disseminando seu aspecto de objeto da administração lato sensu (ADORNO; HORKHEIMER, 2002, p. 44), e instituem um processo de produtividade humana - diuturna, silenciosa e não remunerada -, assentada na tecnologia. A referida produtividade é naturalizada na sociedade mediática e cibercultural a partir da instituição da velocidade (GONÇALVES, 2000, p. 68) como vetor de uma existência que somente se entende e se justifica por aquilo que economicamente produz; e que produz celeremente. A velocidade, diga-se, comparece na história da racionalidade técnica como investimento tecnológico para a superação do tempo e do espaço em seus sentidos tradicionais, que foram considerados, em bloco, barreira para o desenvolvimento do modo capitalista de produção. ${ }^{2}$
A velocidade também é fundamental para a sustentação do discurso capitalista porque permite "a diminuição dos intervalos entre o consumo de uma mercadoria e de outra [construindo] uma espécie de sustentação da satisfação" (GONÇALVES, 2000, p. 69). Em termos operacionais, isso significa produzir cotidianamente uma falta, no sentido de manter 0 sujeito na condição de um desejo sempre atuante e, por essa razão, nunca satisfeito, uma vez que "uma mercadoria consumida não consuma a satisfação, [mas] relança sempre [a referida] falta" (GONÇALVES, 2000, p. 68).

Pode-se dizer, assim, que ao se utilizar da tecnociência para validar sua autoridade na sociedade contemporânea - leia-se sociedade mediática -, o discurso da racionalidade técnica foi engendrado na passagem do discurso universitário para o discurso capitalista. Como discurso universitário, a racionalidade técnica comparece lastreada no conhecimento científico, municiando o sujeito com um repertório positivista, empirista, numérico, que se pretende explicativo, no modo totalizante, da existência do ente humano. Nessa situação insere-se, por exemplo, o discurso do especialista que prescreve o sujeito ideal como aquele normalizado porque seguidor incondicional dos modelos existenciais que representam a saúde perfeita (SFEZ, 1996). Na 
qualidade de discurso capitalista, a racionalidade técnica surge como remédio administrativo ministrado contra as vicissitudes do sujeito. Deste espera-se que siga obedientemente às prescrições normativas e burocráticas - estas nomeadas como comprovadamente eficazes para um imaginado progresso e para a civilização, pelo seu esperado poder de esterilizar 0 ente humano, simbolicamente livrando-o da impudicícia, da imprevisibilidade, da vulnerabilidade, pois essas "debilidades" são vistas como inconvenientes para 0 êxito do empreendimento capitalista.

A sociedade mediática cumpre o papel de esteio da burocracia e do capital, reproduzindo e distribuindo o discurso da racionalidade técnica como verdade sobre o sujeito, dizendo quem ele deve ser no sentido de que ele pode ser apenas um: aquele que reproduz o sujeito ideal como quem está em conformidade com uma determinada ordem. Desse modo, a sociedade mediática se alimenta dos preceitos da racionalidade técnica na medida em que esta pode ser entendida não apenas como um sistema de ideias, mas como uma forma específica do imaginário social moderno, [uma] maneira necessária pela qual os agentes sociais representam para si mesmos 0 aparecer social, econômico e político, de tal sorte que essa aparência, [...] por ser o modo imediato e abstrato de manifestação do processo histórico, é o ocultamento ou a dissimulação do real (CHAUÍ, 2003, p. 3, grifo da autora).

Justamente por trabalhar no espaço lacunar do ocultamento (CHAUÍ, 2003, p. 3) - nos termos antes analisados no contexto da relação dialética entre sujeito e mestre -, a racionalidade técnica alcança eficácia ideológica quando opera um jogo que vai do não revelar ao recusar o não saber, recusar as diferenças, as contradições, para enfraquecer a força de questionamento do sujeito, colocando-se, assim, falsamente fora do processo social-histórico (CHAUÍ, 2003, p. 5-6). A racionalidade técnica e 0 repertório mediático, nessa manobra, podem usufruir do status do discurso competente, como nomeado por Chauí (2003, p. 7), sendo aquele "proferido, ouvido e aceito como verdadeiro ou autorizado [...] porque perdeu os laços com o lugar e 0 tempo de sua origem". 0 discurso competente, em síntese, "é 0 discurso instituído. É aquele no qual a linguagem sofre uma restrição que poderia ser assim resumida: não é qualquer um que pode dizer a qualquer outro qualquer coisa em qualquer lugar e em qualquer circunstância" (CHAUÍ, 2003, p. 7). Trata-se, em última instância, do próprio discurso da racionalidade técnica na sociedade mediática; ou do discurso da sociedade mediática na função do mestre moderno, pressupondo como interlocutor um sujeito barrado pelo significante mestre.

A instituição do discurso competente advém "do processo de burocratização de todas as esferas da vida social, econômica e política, de todas as manifestações culturais" (CHAUÍ, 2003, p. 8) - entenda-se, da adoção da racionalidade técnica como modelo não apenas econômico, mas também social e cultural. Tal burocratização 
instituiu o repertório da autoridade como sendo aquela detentora do conhecimento técnicoespecializado, desenvolvido para imprimir a eficácia existencial e social como extensão e sinônimo da eficácia do capital. 0 repertório da autoridade, nesse contexto, demarca o espaço do sujeito à medida que nomeia modelos de pensamento e de ação, silenciosamente excluindo do devir as possibilidades que não coadunam com os ditames do referido repertório. Significa dizer que para viger o discurso competente exige do sujeito um existir menos, um existir expropriado de possibilidades outras que não aquelas instituídas hegemonicamente. Essa operação de dominação transcorre no espaço da linguagem considerada, aqui, como tessitura que entrelaça 0 verbal, 0 gestual, 0 imagético e 0 inconsciente como uma rede de significantes (LEITE, 2010, p. 33-35) construída ao longo da história psíquica do sujeito.

\section{Referências}

ADORNO, Theodor; HORKHEIMER, Max. Dialéctica

del iluminismo. Madrid: Nacional, 2002.

BASTOS, Aguinaldo; CABRAL, Alexandre Marques; REZENDE, Jonas. Ontologia da violência: 0 enigma da crueldade. Rio de Janeiro: Mauad, 2010. BENJAMIN, Walter. Sobre alguns temas em Baudelaire.

Os Pensadores. São Paulo: Abril Cultural, 1980 [1936a]. . 0 narrador: observações acerca da obra de Nicolau Leskov. Os Pensadores. São Paulo: Abril Cultural, 1980 [1936b].

CASTORIADIS-AULAGNIER, Piera. La violência de la interpretación: del pictograma al enunciado. Buenos Aires: Amorrortu, 2010.

CHAUI, Marilena. Cultura e democracia: 0 discurso competente e outras falas. São Paulo: Cortez, 2003. p. 3-13.

FERRAZ, Flávio Carvalho. Normopatia. São Paulo: Casa do Psicólogo, 2011. (Coleção clínica psicanalítica; 18).

FREUD, Sigmund. História de uma neurose infantil ("O homem dos lobos"), além do princípio do prazer e outros textos (19171920). São Paulo: Companhia das Letras, 2010. p. 293-327.

GONÇALVES, Luiza Helena Pinheiro. 0 discurso do capitalista: uma montagem em curto-circuito. São Paulo: Via Lettera, 2000.

HABERMAS, Jürgen. Técnica e ciência como “ideologia”. Lisboa: Ed. 70, 2006.

HEGEL, Georg Wilhelm Friedrich. Fenomenologia do espírito. Petrópolis: Vozes; Bragança Paulista: Universitária São Francisco, 2007. p. 142-151.

HEIDEGGER, Martin. Ensaios e conferências.

Petrópolis: Vozes; Bragança Paulista: Universitária São Francisco, 2008. p. 11-38.

LACAN, Jacques. O seminário, livro 17: 0 avesso da psicanálise. Rio de Janeiro: Jorge Zahar, 1992.

LEITE, Márcio Peter de Souza. 0 inconsciente está estruturado como uma linguagem. In: CESAROTTO, Oscar (Org.). Ideias de Lacan. São Paulo: Iluminuras, 2010.

LORENZER, Alfred. Bases para una teoría de la socialización. Buenos Aires: Amorrortu, 2001. MARCUSE, Herbert. Cultura e sociedade. Rio de Janeiro: Paz e Terra, 1998. v. 2.

REIS, Angela Pintor dos. 0 glocal e a organização do capital no espaço. In: CONGRESSO BRASILEIRO DE 
CIÊNCIAS DA COMUNICAÇÃO, 32., 2009. Curitiba.

Anais... Curitiba: INTERCOM, 2009. Trabalho

apresentado no IX Encontro dos Grupos/Núcleos de

Pesquisa em Comunicação.

ROUDINESCO, Elisabeth; PLON, Michel. Dicionário

de psicanálise. Rio de Janeiro: Jorge Zahar, 1998.

SFEZ, Lucien. A saúde perfeita: crítica de uma nova utopia. São Paulo: Loyola, 1996.

SOUSA, Mauro Wilton de. Novos cenários no estudo da recepção mediática. In: LOPES, Dirceu Fernandes; TRIVINHO, Eugênio (Org.). Sociedade mediática: significação, mediações e exclusão. Santos, SP:

Universitária Leopoldianum, 2000.

WEBER, Max. A ética protestante e o

"espírito do capitalismo". São Paulo: Companhia das Letras, 2004.

Economia e sociedade. v.1 e v.2. Brasília,

DF: Universidade de Brasília; São Paulo: Imprensa

Oficial do Estado de São Paulo, 1999. 


\section{Subject and discourse of technical rationality in mediatic society}

\section{Abstract}

This essay discusses the conditions in which technical rationality constitutes a composite with mediatic society for the constitution of a normalized subject. To underpin the discussion, relationships are established between construction devices of the subject and devices of three types of discourse, to wit, the modern master's discourse, the university discourse and the competent discourse. Subject and discourse are considered conceptually within the context of Lacanian theory, with discourse understood as the social bond from which the subject builds himself and upon which he projects himself. Technical rationality is considered an ideology of domination, in the terms developed by Marcuse, Habermas, Weber and Heidegger.

\section{Keywords}

Technical rationality. Mediatic society. Subject. Discourse. Domination.

\section{Sujeto y discurso de racionalidad técnica en la sociedad mediática}

\section{Resumen}

Este ensayo discute en qué condiciones la racionalidad técnica constituye un compuesto con la sociedad mediática para la constitución de un sujeto normalizado. Como apoyo a la discusión son desarrolladas relaciones entre dispositivos de construcción del sujeto y dispositivos de tres tipos de discurso, a saber, el del maestro moderno, el universitario y el competente. Sujeto y discurso son conceptualmente considerados en el contexto de la teoría lacaniana, siendo el discurso comprendido como el enlace social a partir del cual el sujeto se construye y sobre el cual se proyecta. La racionalidad técnica es considerada como ideología de dominación, en los términos desarrollados por Marcuse, Habermas, Weber y Heidegger.

\section{Palabras clave}

Racionalidad técnica. Sociedad mediática. Sujeto. Discurso. Dominación. 


\section{Expediente}

A revista E-Compós é a publicação científica em formato eletrônico da Associação Nacional dos Programas de Pós-Graduação em Comunicação (Compós). Lançada em 2004, tem como principal finalidade difundir a produção acadêmica de pesquisadores da área de Comunicação, inseridos em instituições do Brasil e do exterior.
E-COMPÓS I www.e-compos.org.br I E-ISSN 1808-2599

Revista da Associação Nacional dos Programas

de Pós-Graduação em Comunicação.

Brasília, v.15, n.1, jan./abr. 2012.

A identificação das edições, a partir de 2008

passa a ser volume anual com três números.

\section{CONSELHO EDITORIAL}

Afonso Albuquerque, Universidade Federal Fluminense, Brasil Alberto Carlos Augusto Klein, Universidade Estadual de Londrina, Brasil Álvaro Larangeira, Universidade Tuiuti do Paraná, Brasil Ana Carolina Damboriarena Escosteguy, Pontifícia Universidade Católica do Rio Grande do Sul, Brasil

Ana Gruszynski, Universidade Federal do Rio Grande do Sul, Brasil Ana Silvia Lopes Davi Médola, Universidade Estadual Paulista, Brasil André Luiz Martins Lemos, Universidade Federal da Bahia, Brasil Ângela Freire Prysthon, Universidade Federal de Pernambuco, Brasil Angela Cristina Salgueiro Marques, Faculdade Cásper Líbero (São Paulo), Brasil Antônio Fausto Neto, Universidade do Vale do Rio dos Sinos, Brasil Antonio Carlos Hohlfeldt, Pontifícia Universidade Católica do Rio Grande do Sul, Brasil Antonio Roberto Chiachiri Filho, Faculdade Cásper Líbero, Brasil Arthur Autran Franco de Sá Neto, Universidade Federal de São Carlos, Brasil Benjamim Picado, Universidade Federal Fluminense, Brasil César Geraldo Guimarães, Universidade Federal de Minas Gerais, Brasil Cristiane Freitas Gutfreind, Pontifícia Universidade Católica do Rio Grande do Sul, Brasil Denilson Lopes, Universidade Federal do Rio de Janeiro, Brasil Eduardo Peñuela Cañizal, Universidade Paulista, Brasil Eduardo Vicente, Universidade de São Paulo, Brasil Eneus Trindade, Universidade de São Paulo, Brasil Erick Felinto de Oliveira, Universidade do Estado do Rio de Janeiro, Brasil Florence Dravet, Universidade Católica de Brasilia, Brasil Gelson Santana, Universidade Anhembi/Morumbi, Brasil Gislene da Silva, Universidade Federal de Santa Catarina, Brasil Guillermo Orozco Gómez, Universidad de Guadalajara Gustavo Daudt Fischer, Universidade do Vale do Rio dos Sinos, Brasil Hector Ospina, Universidad de Manizales, Colômbia Herom Vargas, Universidade Municipal de São Caetano do Sul, Brasil leda Tucherman, Universidade Federal do Rio de Janeiro, Brasil Inês Vitorino, Universidade Federal do Ceará, Brasil Jnice Caiafa, Universidade Federal do Rio de Janeiro, Brasil Jay David Bolter, Georgia Institute of Technology Jeder Silveira Janotti Junior, Universidade Federal de Pernambuco, Brasil João Freire Filho, Universidade Federal do Rio de Janeiro, Brasil John DH Downing, University of Texas at Austin, Estados Unidos José Afonso da Silva Junior, Universidade Federal de Pernambuco, Brasil
José Carlos Rodrigues, Pontifícia Universidade Católica do Rio de Janeiro, Brasil José Luiz Aidar Prado, Pontifícia Universidade Católica de São Paulo, Brasil José Luiz Warren Jardim Gomes Braga, Universidade do Vale do Rio dos Sinos, Brasil Juremir Machado da Silva, Pontifícia Universidade Católica do Rio Grande do Sul, Brasil Laan Mendes Barros, Universidade Metodista de São Paulo, Brasil Lance Strate, Fordham University, USA, Estados Unidos Lorraine Leu, University of Bristol, Grã-Bretanha Lucia Leão, Pontifícia Universidade Católica de São Paulo, Brasil Malena Segura Contrera, Universidade Paulista, Brasil Márcio de Vasconcellos Serelle, Pontifícia Universidade Católica de Minas Gerais, Brasil Maria Aparecida Baccega, Universidade de São Paulo e Escola Superior de Propaganda e Marketing, Brasil Maria das Graças Pinto Coelho, Universidade Federal do Rio Grande do Norte, Brasil Maria Immacolata Vassallo de Lopes, Universidade de São Paulo, Brasil Maria Luiza Martins de Mendonça, Universidade Federal de Goiás, Brasil Mauro de Souza Ventura, Universidade Estadual Paulista, Brasil Mauro Pereira Porto, Tulane University, Estados Unidos Mirna Feitoza Pereira, Universidade Federal do Amazonas, Brasil Nilda Aparecida Jacks, Universidade Federal do Rio Grande do Sul, Brasil Paulo Roberto Gibaldi Vaz, Universidade Federal do Rio de Janeiro, Brasil Potiguara Mendes Silveira Jr, Universidade Federal de Juiz de Fora, Brasil Renato Cordeiro Gomes, Pontifícia Universidade Católica do Rio de Janeiro, Brasil Robert K Logan, University of Toronto, Canadá

Ronaldo George Helal, Universidade do Estado do Rio de Janeiro, Brasil Rose Melo Rocha, Escola Superior de Propaganda e Marketing, Brasil Rossana Reguillo, Instituto de Estudos Superiores do Ocidente, Mexico Rousiley Celi Moreira Maia, Universidade Federal de Minas Gerais, Brasil Sebastião Carlos de Morais Squirra, Universidade Metodista de São Paulo, Brasil Sebastião Guilherme Albano da Costa, Universidade Federal do Rio Grande do Norte, Brasil

Simone Maria Andrade Pereira de Sá, Universidade Federal Fluminense, Brasil Tiago Quiroga Fausto Neto, Universidade de Brasília, Brasil

Suzete Venturelli, Universidade de Brasilia, Brasil Valério Cruz Brittos, Universidade do Vale do Rio dos Sinos, Brasil Valerio Fuenzalida Fernández, Puc-Chile, Chile Veneza Mayora Ronsini, Universidade Federal de Santa Maria, Brasil Vera Regina Veiga França, Universidade Federal de Minas Gerais, Brasil

\section{COMISSÃO EDITORIAL}

Adriana Braga I Pontifícia Universidade Católica do Rio de Janeiro, Brasil

Felipe Costa Trotta I Universidade Federal Fluminense, Brasil

CONSULTORES AD HOC

Bruno Campanella, Universidade Federal Fluminense, Brasil

Gisela Grangeiro da Silva Castro, Escola Superior de Propaganda e Marketing, Brasi José Carlos Ribeiro, Universidade Federal da Bahia, Brasil

Luciana Panke, Universidade Federal do Paraná, Brasil

Micael Herschmann, Universidade Federal do Rio de Janeiro, Brasil

Tânia Márcia Cezar Hoff, Escola Superior de Propaganda e Marketing, Brasil

Virginia da Silveira Fonseca, Universidade Federal do Rio Grande do Sul, Brasil

EDIÇÃO DE TEXTO E RESUMOS I Susane Barros

SECRETÁRIA EXECUTIVA I Juliana Depiné

EDITORAÇÃO ELETRÔNICA I Roka Estúdio
COMPós I www.compos.org.br

Associação Nacional dos Programas de Pós-Graduação em Comunicação

Presidente

Julio Pinto

Pontifícia Universidade Católica de Minas Gerais, Brasil

juliopinto@pucminas.br

Vice-presidente

Itania Maria Mota Gomes

Universidade Federal da Bahia, Brasil

itania@ufba.br

Secretária-Geral

Inês Vitorino

Universidade Federal do Ceará, Brasil

inesvict@gmail.com 